\title{
The COVID-19 pandemic in an aging world
}

David S Reher [1], Miguel Requena* [2], Gustavo De Santis [3], Albert Esteve [4], Massimo Livi Bacci [3], Mojgan Padyab [5], Glenn Sandström [5]

*Corresponding author: mrequena@poli.uned.es

[1] Universidad Complutense de Madrid (Spain)

[2] UNED (Spain)

[3] Università degli Studi di Firenze (Italy)

[4] Centre d'Estudis Demogràfics (Spain)

[5] Umeå University (Sweden)

\section{Key words}

COVID-19, population aging, co-residence, living alone, rest homes, contagion, lethality, epidemics

\begin{abstract}
Since death rates from the COVID-19 are highest among the oldest, the impact of the current pandemic in a given society depends to a large extent on the share of elderly persons and their living arrangements. Whereas the former is well known, the latter is not. Arguably, contagion itself and the severity of its symptoms are likely to vary among elderly persons living alone, co-residing with family members or dwelling in institutions. Arguments in favour and against the premise that single-living elderly are better able to self-isolate can be made. Long-term care facilities have worsened the effects of the epidemic because they have often become death traps in some but not all countries. Once contagion takes place, living arrangements can make a huge difference in the way the disease can be managed by the individual, his family and society. Properly understanding the dynamics of contagion and the handling of the disease in terms of living arrangements of elderly people is essential for effectively tackling future outbreaks of similar epidemics.
\end{abstract}




\section{The COVID-19 pandemic in an aging world}

\section{The epidemic becomes a pandemic}

The COVID-19 epidemic began in China but has spread rapidly to much of the world. It has become the most relevant health issue in many decades, with poorly known contagion levels (due to lack of adequate testing) and currently 83,476 deaths (20-04-08). ${ }^{1}$ Considering the lack of representative studies using antibodies, currently our best "guestimate" of its basic characteristics suggests that there is an important percentage of asymptomatic contagions (approximately 30\%), a high percentage (55\%) with mild to moderate symptoms, about $10 \%$ of contagions with severe symptoms requiring hospitalization and about $5 \%$ of all contagions requiring intensive care and ventilation (Razai, et al. 2020). Deaths from COVID-19 correspond to these last two categories. A key characteristic of this virus is its ability to spread undetected, efficiently and quickly, ultimately thwarting the efforts of authorities to afford reliable estimates of its spread. It has put public health systems to a severe test and often overwhelmed their ability to manage the avalanche of severe cases acceptably well.

One of the main characteristics of COVID-19 is that it is especially widespread and lethal among elderly persons, in particularly those beyond 70 years of age. In the initial phase of the epidemic when it was restricted for the most part to China, death rates were 11.4 times higher among those 80+ than they were for people 50-59. ${ }^{2}$ This age structure of death rates among confirmed cases has been corroborated recently for the COVID-19 epidemic in Spain, Italy and France. ${ }^{3}$ Death rates tend to be higher among men and among people with co-morbidities. However, the asymptomatic onset of the virus together with the nearly unknown proportion of asymptomatic cases, makes it nearly impossible to register contagion and its relation to age reliably. Notwithstanding, the key challenge of the COVID-19 epidemic for health systems is related to the rate at which people needing different types of intensive care bunch together, quickly overwhelming available hospital beds or the supply of respirators, for example. COVID-19 constitutes the most important challenge for health care systems in recent memory, with often-disappointing results.

\section{The societal contexts of the pandemic}

Here a crucial determining factor will be the relative size of the elderly population and the extent to which they are exposed to contagion. From a demographic standpoint, we find substantial differences in the share of the population that is aged 65+ across developed and developing countries but also substantial differences among the developed nations. These demographic contrasts together with differences in the living arrangements and solutions for the care of the frailest elderly are crucial factors in calibrating the gravity of the COVID-19 epidemic and the ability of different societies to combat it successfully. In this text we will address some potential implications of these demographic contrasts, primarily within the

\footnotetext{
${ }^{1}$ Centre for Systems Science and Engineering (CSSE) at Johns Hopkins University. (2020, April 4). Coronavirus COVID-19 Global Cases Johns Hopkins University (CSSE). https://www.arcgis.com/apps/opsdashboard/index.html\#/bda7594740fd40299423467b48e9ecf6.

${ }^{2}$ As reported in https://www.worldometers.info/coronavirus/coronavirus-age-sex-demographics/.

${ }^{3}$ Official statistics for Spain show that the vast majority of serious complications -including deaths- associated with COVID-19 are found in people of above 70 and often 80 years of age. See, for example, Figures 2-3 and Tables 3.1-3.3 in Informe n $n^{\circ}$ 19. Situación de COVID-19 en España a 1 de abril de 2020. Equipo COVID-19. RENAVE. CNE. CNM (ISCIII); https://www.isciii.es/QueHacemos/Servicios/VigilanciaSaludPublicaRENAVE/EnfermedadesTransmisibles/Pagi nas/InformesCOVID-19.aspx. For Italy see Onder, Rezza and Brusaferro (2020). See also: INED: https://dccovid.site.ined.fr/en/presentation.
} 
developed world, and how they affect different societies potential to cope with the current epidemic.

In recent decades, there have been important shifts around the world linked to population aging and to the position of the elderly in society that have significant implications for the way COVID-19 affects society. Briefly stated, these are:

- Over the past half century in the most developed world, and more recently in the developing world, there has been an important process of societal aging that has led to an increase in the proportion and the actual number of elderly in society. In countries where this process is more advanced, the relative weight of the elderly is highlighted by far faster population growth rates among the oldest age groups ( $>80$ or higher) than in other age ranges normally considered to be elderly as well (say, 60-69). This shift in population age structures has fuelled fears for the stability of all forms of well-being based on intergenerational transfers of goods and services; specifically, here, health care systems. Within this general situation, the faster growth rates of the highest age groups have posed a wide array of challenges ranging from people's ability to save for the final stages of their own lives to the actual number of people with given healthrelated issues. The age of aging is a worldwide phenomenon that is unquestionably most advanced in highly developed societies with long-standing levels of very low fertility, including a number of developed East Asian nations (Taiwan, South Korea, Singapore, Japan). In much of the developing world, this an issue for the future, but in some highly developed countries it is very much an issue of the present. The timing of major shifts in fertility in the recent past explain disparities in the timing of these processes (Reher, 2015).

- Associated with the general process of societal aging, there has been an important growth in the proportion of elderly living on their own. ${ }^{4}$ There are multiple causes for this shift, including the incidence of divorce, differential life expectancy by sex during mid- and late-life, the out-migration of younger family members, the desirability of living alone and people's ability to do so, the availability of other options for coresidence in later life, including living with offspring and kin, or in institutional contexts. As a result of all of these factors, at present percentages of living alone have reached extremely high levels, as high as $50 \%$ or more among women (aged 75-79) and $20-30 \%$ among men. Levels are by far the highest in the most developed nations of the world, but there is some indication that they are on the rise everywhere (Esteve et al, 2020). Recent research has also shown a sharp growth in the proportion living alone in later life although, in some countries where it peaked relatively early (Nordic countries, the UK, the USA), there has been a moderate decline in these rates over the past 20 years, though not in the actual number of elderly living alone (Reher and Requena, 2019). Even so, rates for women above 65 who live alone in many countries continue to be well in excess of $30-35 \% .^{5}$ In sum, in the developed world, living alone represents an important component in people's residential options as they age.

- An important characteristic of aging societies is the increasing importance of institutional living arrangements for people during later life. In some countries, these

\footnotetext{
${ }^{4}$ For details of this research, see Esteve et al. (2020); Padyab et al. (2019); Reher and Requena (2017); (2018); Requena et al. (2019).

${ }^{5}$ Recent UN data show that living alone (both sexes) among people aged 60 and over is often in excess of 20 or even $30 \%$. See: UN-DESA (2017): annex 3. https://www.un.org/en/development/desa/population/publications/pdf/ageing/LivingArrangements.pdf,
} 
arrangements are public while in others they are the result of private initiative. Everywhere, they constitute the third option for people as they age, situated alongside living with others (mainly with spouses or other kin) and, of course, living alone. For the EU, official country-level data for 2011 show that between 2-25\% of peopled aged $85+$ live in institutional households (Eurostat 2015). The importance of this residential option has grown in recent years.

\section{Implications}

These structural characteristics of the aging process in the developed world have important implications for the COVID-19 epidemic and the way it has developed to date.

Holding other factors constant in the detection and the management of the epidemic, this means that the importance of the epidemic will tend to be higher in societies where the weight of the elderly is highest (Kashnitsky and Aburto, 2020; Dudel et al, 2020; Dowd et al. 2020). This effect is multiplied by the prevalence of co-morbidities that will also tend to be higher among the oldest. Finally, despite the fact that relatively little is known about the rate of contagion among people of different ages, the total death rate in different contexts will be highly dependent on: (1) Population age structure (the share of total population older than 70 that experience much higher deaths rates than younger individuals, and (2) The proportion of the population $70+$ exposed to contagion. The extent to which $70+$ can be shielded from contagion will have a strong influence on the number of deaths, though inadequate testing currently makes it impossible to understand the age/contagion trade off properly. At the very least, however, we know that rates of contagion are likely to be high among the oldest old but their symptoms will be far more serious, ultimately leading to higher death rates among them. When these age groups represent a relatively higher percentage of the total population at risk, death rates should be correspondingly higher.

Another potentially important demographic factor related to aging and influencing the impact of COVID-19 in different societies are differences in household structure and living arrangements. The importance of people living alone, especially in later life, has grown enormously and will have important implications for the severity of the COVID-19 epidemic. Research on the links between contagion and residential status with respect to the COVID-19 epidemic is sorely lacking at this stage. Whether or not elderly living on their own are more or less likely to become infected is a matter of conjecture and theoretical arguments can be given both in favour and against. It is well known that the baseline health of elderly people living alone tends to be higher than it is for those living with others, mostly because during old age prior health is a pre-requisite for living alone (Reher and Requena, 2020). Moreover, at least in theory, individuals living alone have greater opportunities to self-isolate and this could potentially reduce their rates of COVID-19 contagion. The problem is that total self-isolation is virtually impossible, especially among the oldest old. This is especially relevant for those who must rely on outside support for supplies (including medication for chronic illness), medical attention and social contact (Priest, 2020). Where kin are available for this support, it will reduce the need of single elderly to expose themselves to contagion at pharmacies, grocery shops etc. but may, in fact, be a source of contagion. Conversely, it is also true that living alone might have only a short-run positive health effect that could give way to long-run negative effects if isolation persists over time and leads to a meaningful decrease in social contacts and support.

In the long run, individuals living with spouses are likely to be better placed both for shortrun and for long-run health and wellbeing and, conversely, individuals living in 
multigenerational families -and certainly those in institutions- are the most poorly positioned, at least in times of epidemic disease (Requena and Reher, 2020; Frisch and Simonsen, 2013; Koskinen et al, 2007). Elderly individuals in living arrangements that expose them to contagion, either from younger household members or staff at institutions, are likely to constitute a highly vulnerable group. The studies linking residential status and the likelihood of death cited above, as interesting as they are, do not deal with highly contagious environments as much as they do with chronic disease and other causes of death. There is much to be done on the links between residential status and health, both in times of epidemic disease and otherwise.

After contagion, the presence of a co-resident at home, especially when it involves a spouse, becomes a vital part care and is especially relevant for any decision as to whether or not a person is taken to an intensive care facility or, conversely, is moved into a nursing home or to some other form of group quarters. This is mostly the case when initial symptoms do not require immediate assisted ventilation or other specialized care. Here, living with another person(s) offers the (at least theoretical) possibility of weathering the epidemic at home. It also facilitates the communication of the health situation to local health authorities. Considering the enormous problems affecting many intensive care units that have characterized much of this epidemic, staying at home may have long-run beneficial effects, at least in some situations. People living alone do not have this sort of in-house buffer for decisions regarding treatment. From a slightly different perspective, this means that living alone among the elderly by definition removes obstacles to their hospitalization and intensive care in case of serious contagion and this contributes to the stress on, and potential collapse of, health care systems during the peak period of any epidemic. In sum, living alone tends to make managing the disease (or the epidemic) more difficult for the infected individual, for his family and for society.

Institutional living represents an intermediate residential strategy whose importance in developed countries has increased substantially because it is a middle, non-family option for co-residence. In many countries, and especially in Italy and in Spain, these residences have become veritable death traps for elderly residents because they have often propagated the contagion without the adequate means of taking care of seriously ill residents. Recently, similar problems have arisen in Sweden where the Public Health Agency [Folkhälsomyndigheten] suspects that this has been caused be the asymptomatic spread of contagion from staff to residents. In Stockholm, currently the epicentre of the epidemic in Sweden, one third of all nursing homes have been affected by contagion. In a country such as Sweden that has a relatively large proportion of the oldest-old in institutional care, the asymptomatic spread of the disease among care staff and a lack of protective equipment might prove to be a massive challenge to the COVID-19 response and a source of high mortality among the oldest-old (Löfvenberg, J. 2020, April 1). The baseline health of individuals entering long-term care facilities is poor by definition and everywhere, when inappropriately isolated, they have proven to be a source of effective propagation of infection and seldom have they been in a place with the capacity to handle massive experiences of contagion. Equally important, rest homes themselves appear to have often been a de facto hindrance for the ability of seriously ill patients to move into ICUs at large hospitals, themselves swamped by desperate demand.

Innovative research on these issues is necessary if we are to understand the spread of the Covid-19 epidemic properly. The key question involves linking contagion and the ultimate outcome of the illness to the social and economic characteristics of people and, specifically, to 
the precise co-residential situation of people and their interactions with others outside the coresidential unit before, during and after the epidemic. This type of research will not only clarify the precise paths taken by the epidemic itself, but will also help us identify more precisely the truly vulnerable groups in society and, ultimately, implement the policies most likely to limit the spread of illness. Representative retrospective surveys of epidemic survivors and of the family members of those who died offer a potential vehicle for this type of research.

\section{Brief conclusions}

We can expect that population aging, high levels of single living during old age and widespread living in overcrowded and understaffed communal residences will tend to make the social, health and demographic effects of the COVID-19 worse, though empirical proof of this, of course, continues to be essential. This explains, in part, the fact that to date the impact of the epidemic appears to be highest in the densely populated developed world, especially in those countries where aging is most advanced, single living during old age is a relevant residential option, and institutional communal residences are widespread. These effects may be enhanced by the existence of relatively close-knit family systems in many parts of the developed world that provide the type of on-going contact that could contribute to the spread of contagion (Reher, 1998; 2019). These characteristics of society were present long before the explosion of the COVID-19 pandemic and will continue to be relevant after the worst stage is past.

Note. This paper has benefitted from the input of all of the authors as well as the very helpful comments from Ronald D. Lee (Berkeley) and Carla Obermeyer (America University of Beirut).

\section{References}

Center for Systems Science and Engineering (CSSE) at Johns Hopkins University. Coronavirus COVID-19 Global Cases Johns Hopkins University (CSSE). https://gisanddata.maps.arcgis.com/apps/opsdashboard/index.html\#/bda7594740fd40299423467b4 8e9ecf6. Accessed 4 April 2020

Dowd, Jennifer Beam, Valentina Rotondi, Liliana Andriano, David M Brazel, Per Block, Xuejie Ding, Yan Liu, Melinda C Mills (2020) "Demographic science aids in understanding the spread and fatality rates of COVID-19," Preprint medRxiv: https://doi.org/10.1101/2020.03.15.20036293

Dudel, Christian, Tim Riffe, Enrique Acosta, Alyson A. van Raalte, Mikko Myrskyla (2020) "Monitoring trends and differences in COVID-19 case fatality rates using decomposition methods: Contributions of age structure and age-specific fatality," Preprint medRxiv; https://doi.org/10.1101/2020.03.31.20048397

Esteve, Albert, David S. Reher, Rocío Treviño, Pilar Zueras, Anna Turu (2020) "Living alone over the life course: Cross-national variations on an emerging issue," Population and Development Review 46(1): 169-189; https://doi.org/10.1111/padr.12311

Eurostat (2015) People in the EU: who are we and how do we live? Chapter 6: An ageing society focus on the elderly, 145-148. ISSN 2443-8219.

Frisch, Morten and Jacob Simonsen (2013) "Marriage, cohabitation and mortality in Denmark: national cohort study of 6.5 million persons followed for up to three decades (1982-2011)," Int J Epidemiol. 2013 Apr; 42(2):559-78. doi: 10.1093/ije/dyt024. 
INED (Institut National d'Études Demographiques). https://dc-covid.site.ined.fr/en/presentation

Informe no 19. Situación de COVID-19 en España a 1 de abril de 2020. Equipo COVID-19. RENAVE. CNE. CNM (ISCIII);

https://www.isciii.es/QueHacemos/Servicios/VigilanciaSaludPublicaRENAVE/EnfermedadesTran smisibles/Paginas/InformesCOVID-19.aspx.

Kashnitsky, Iyla and José Manuel Aburto (2020) "COVID-19 in unequally ageing European regions," OSFPREPRINTS, DOI:10.31219/osf.io/abx7s.

Koskinen, Seppo, Kaisla Joutsenniemi, Tuija Martelin, Pekka Martikainen (2007) "Mortality differences according to living arrangements," International Journal of Epidemiology, Volume 36, Issue 6, December 2007, Pages 1255-1264, https://doi.org/10.1093/ije/dym212

Lazzerini, Marzia and Giovanni Putoto (2020) "COVID-19 in Italy: momentous decisions and many uncertainties," The Lancet Global Health, Published: March 18, 2020, DOI:https://doi.org/10.1016/S2214-109X(20)30110-8

Löfvenberg, J. (2020, April 1). Smitta på minst 29 boenden för äldre i Stockholm. SVT Nyheter. https://www.svt.se/nyheter/lokalt/stockholm/smittade-pa-boende-for-aldre-i-stockholm. Accessed 4 April 2020

Onder, Graziano, Giiovanni Rezza and Silvio Brusaferro (2020) "Case-fatality rate and characteristics of patients dying in relation to COVID-19 in Italy," JAMA. Published online March 23, 2020. doi:10.1001/jama.2020.4683.

Padyab, Mojgan, David Reher, Miguel Requena, Glenn Sandström (2019) "Going it alone in later life: A comparative analysis of elderly women living in Sweden and Spain," Journal of Family Issues 48(8): 1038-1064; https://doi.org/10.1177/0192513X19831334

Priest, Kelsey C. (2020) "The COVID-19 Pandemic: Practice and policy considerations for patients with opioid use Health Affairs Blog. http://healthaffairs.org/blog/10.1377/hblog20200331.557887

Razai, Mohammad S, Katja Doerholt, Shamez Ladhani \& Pippa Oakeshott (2020). Coronavirus disease 2019 (covid-19): a guide for UK GPs. BMJ, 368. https://doi.org/10.1136/bmj.m800

Reher, David S. (1998). "Family ties in Western Europe: persistent contrasts." Population and Development Review, vol. 24, no. 2, 203-234.

Reher, David S. (2015) "Baby booms, busts, and population ageing in the developed world," Population Studies: A Journal of Demography, 69:sup1, S57-S68, DOI: 10.1080/00324728.2014.963421.

Reher, David S (2019) "The Aftermath of the Demographic Transition in the Developed World: Interpreting Enduring Disparities in Reproductive Behavior," Population and Development Review. https://doi.org/10.1111/padr.12266

Reher, David and Miguel Requena (2017) "Elderly women living alone in Spain: The importance of having children," European Journal of Ageing 14 (3): 311-322; doi:10.1007/s10433-017-0415-6

Reher, David and Miguel Requena (2018) "Living alone in later life: A global perspective," Population and Development Review 44 (3): 427-454; https://doi.org/10.1111/padr.12149

Reher, David and Miguel Requena (2019) "Long-term trends in living alone in later life in the United States, 1850-2015, The History of the Family; DOI:10.1080/1081602X.2019.1696217.

Requena, Miguel, David Reher, Mojgan Padjab and Glenn Sandström et al. (2019) "Women living alone in later life. A multicountry comparative analysis," Population, Space and Place 25 (7): 116. DOI: $10.1002 / \mathrm{psp} .2269$

Requena, Miguel and David Reher (2020) "Residential status and health in middle and late life: a population-based study with new data from Spain," BMJ Open 2020; 0:e033330. doi:10.1136/bmjopen-2019-033330. 
United Nations-DESA (2017) Living Arrangements of Older Persons: A Report on an Expanded International Dataset, https://www.un.org/en/development/desa/population/publications/pdf/ageing/LivingArrangements .pdf

Worldometers; https://www.worldometers.info/coronavirus/coronavirus-age-sex-demographics/ 